\title{
BIOTRANSFORMATION OF INDOLE ALKALOID BY TERRESTRIAL STREPTOMYCES GW $14 / 587$ STRAIN INTO A SELECTIVE PHYCOTOXIC AGENT
}

\author{
E.G. Haggag ${ }^{1}$ and H. Laatsch ${ }^{2}$ \\ ${ }^{1}$ Department of Pharmacognosy, Faculty of Pharmacy, Helwan University at Ain Helwan, \\ Cairo, 11795 Egypt \\ ${ }^{2}$ Department of Organic Chemistry, George-August-University, Tammann Strasse 2, \\ Gottingen, 27570, Germany
}

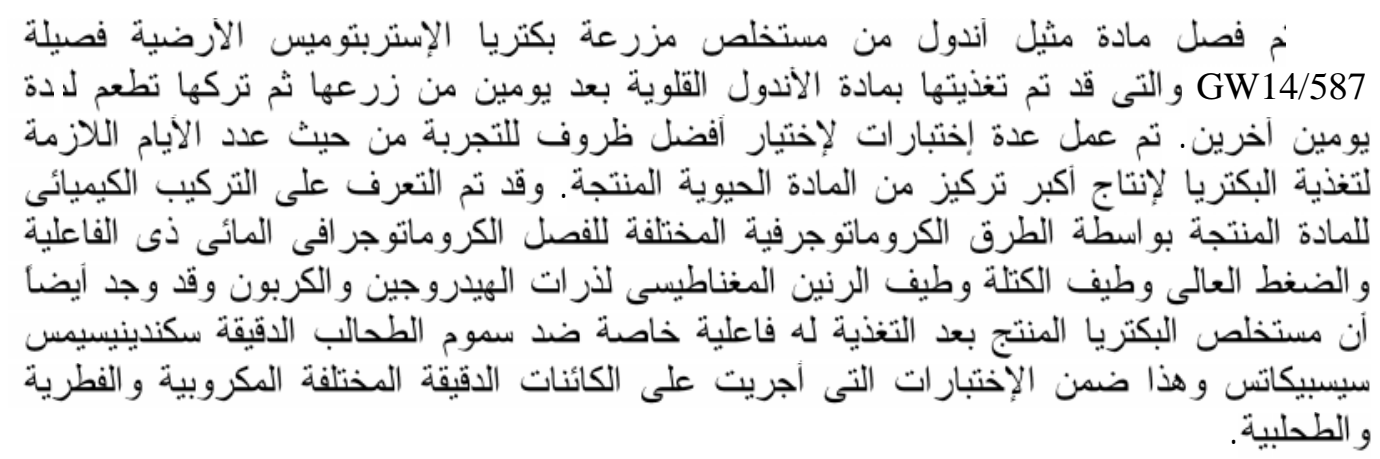

Methyl indole was isolated as a metabolite from the culture broth of terrestrial Streptomyces GW 14/587 strain which was fed with indole after two days growth and then inoculated for another two, three and four days to optimize the experiment condition for highest metabolite concentration. The structure of the isolated methyl indole was established using spectral techniques of HPLC-MS, EI-MS, ${ }^{1} \mathrm{H}$ and ${ }^{13} \mathrm{CNMR}$. Also the bacterial extract showed a high selective phycotoxic activity against Scendensmus subspicatus among the different tested microalgae, yeast, fungi and bacteria.

\section{INTRODUCTION}

Microorganisms, in particular bacteria, have been found to have a profound effect on the development of medical sciences. Since the discovery of penicillin in 1929, intensive studies of mainly soil derived bacteria and fungi have shown that microorganisms are a rich source of new biologically active secondary metabolites. ${ }^{1-3}$ Over the past 60 years between 30,000 and 50,000 natural products have been discovered from microorganisms. More than 10,000 of these compounds were found to be biologically active, of which more than 8,000 are antibiotics and anti-tumor agents. Today, over 100 microbial products continue to be used clinically as antibiotics and anti-tumor agents. ${ }^{4}$
A large variety of indole alkaloids have been isolated from marine organisms, ${ }^{5-10}$ among which is the marine Streptomycete. ${ }^{11-14}$ Terrestrial Streptomyctes was also investigated for its antibiotic contents. ${ }^{15,16}$ Indole derivatives are common secondary metabolites from microorganisms; more than 1000 derivatives have been reported. ${ }^{4}$

Experiments on feeding bacteria with different compounds and the isolation of their secondary metabolites, preferably those of biological activities, is a new trend.

Here we report on the indole feeding experiment of terrestrial Streptomycete GW $14 / 587$ establishing the ultimate inoculation period of the fed media for the bacteria to produce a secondary metabolite which has been isolated, purified and identified. In addition, we report on the antibiotic effect of the extract of 
indole fed bacteria on different microorganisms and micro algae.

\section{EXPERIMENTAL}

\section{Materials}

Terrestrial Streptomycete GW 14/587 was obtained from the collection of Alfred-Wegner Institute of Polar and Meeresforchung, Bremerhaven, Germany. Escherichia coli (Strain ATCC 25922), Bacillus subtilis (Strain Bs 1091-1), Streptomyces viridochromogenes (Strain Tu 57), Staphylococcus aurens (Strain Sau 1091-5), Mucor miehei (Tu 284), Candida albicans (HBI 101), Chlorella vulgaris (SAG 211-11b), Chlorella sorokiniana (SAG 2118K) and Scenedesmus subspicatus (SAG 8681) were all obtained from stocks maintained at the Department of Organic Chemistry, GeorgeAugust-University, Gottingen, Germany.

Indole was obtained from Sigma - Aldrich corporation (Germany) and used in a concentration of $400 \mathrm{mg} / \mathrm{L}$ culture media using ethanol as a solvent.

Ehrlich's reagent: $0.5 \mathrm{~g}$ of $\rho$-dimethyl amino benzaldhyde (Sigma - Aldrich corporation, Germany) was dissolved in $50 \mathrm{ml}$ methanol and then $2 \mathrm{ml}$ of conc. HCL was added.

Silica gel Alugra SIL G/UV 254 (MachereyNagel GmbH and Co., Duren, Germany) precoated aluminum sheets were used for thin layer chromatography. Silica gel Merck 11695 (Sigma-Aldrich Corporation, Germany) was used for preparative TLC.

\section{Equipment}

${ }^{1} \mathrm{H}$ and ${ }^{13} \mathrm{C}$ NMR spectra were measured on a varian unity $300 \quad(300.145 \mathrm{MHz})$ spectrometer in $\mathrm{CDCL}_{3}$ with TMS as internal standard.

EI-MS was recorded on a varian MAT 731 $(70 \mathrm{eV})$ mass spectrometer, preparative HPLCMS was performed using an RP18 column (Eurochrome Eurosphere RP 100-C18, 5um) using a Jasco diode array multiple wave length detector (MD-910) in a scanning range of 195$650 \mathrm{~nm}$, connected to (+ve) ESI Finnigan MAT 95 A mass spectrometer. Retention times were measured on a $4 \times 250 \mathrm{~nm}$ (Eurochrome RP18 column $60 \mathrm{~A}^{\circ}$, 5um) with a linear acetonitrilewater azeotrope / water gradient $(\mathrm{t}=0: 10 \%$ azeotrope, $\mathrm{t}=25$ minutes: $100 \%$ azeotrope: isocratic for another 50 minutes).

\section{Methods}

Preparation of yeast-malt extract medium ${ }^{17}$

Malt extract (10 g), yeast extract $(4 \mathrm{~g})$ and anhydrous glucose $(4 \mathrm{~g})$ were dissolved in distilled water $(1 \mathrm{~L})$. Before sterilization, the $\mathrm{pH}$ was adjusted to 7.8 by addition of $2 \mathrm{~N}$ $\mathrm{NaOH}$.

\section{Fermentation and feeding}

Well-grown agar cultures of Streptomyeces GW 14/587 served to inoculate eight 1-Litre-Erlenmyer flask each containing $250 \mathrm{ml}$ of yeast malt extract media. The flasks were incubated for two days at $28^{\circ}$ with shaking at $95 \mathrm{rpm}$ to grow. The cultures were then fed with $5 \mathrm{ml}$ of prepared indole solution in ethanol in the two following days leaving one group of culture without feeding as a control group. Indole fed cultures were divided into three groups in respect to incubation period; one group was incubated for two days after being fed, the second group was incubated for three days and the third was incubated for four days after being fed; so as to give 4-, 5and 6-day-old cultures, respectively. All culture flasks were taken out of the shaker and allowed to freeze and lyophilized for 12-24 hours.

\section{Extraction $^{11}$}

The fermentation broth for each group was separately filtered with the aid of celite and the resulting mycelial cake was extracted three times with ethyl acetate each with $250 \mathrm{ml}$ with sonication for 15 minutes. Also the filtrate broth was extracted three times using ethyl acetate. All the ethyl acetate extract from filtrate and mycelia cake, for each group, were combined together, concentrated under reduced pressure and examined by TLC, using dichloromethane/ cyclohexane 8:2 as a solvent system and Ehrlich's reagent as a spray reagent for spot coloring.

\section{Separation}

The concentrates of the 4,5 and 6 days old cultures were separately subjected to preparative thin layer chromatography (PTLC) using cyclohexane / dichloromethane (1:1) as an eluting solvent system. The plates were redeveloped three times to afford a white solid 
metabolite (12, 9 and $8 \mathrm{mg}$ of four, five and six day-old culture concentrates, respectively). It gave a dark purplish fluorescence under UV at $254 \mathrm{~nm}, \quad \mathrm{R}_{\mathrm{f}}=0.60$ cyclo hexane : dichloro methane; $1: 1$, an intense blue color when sprayed with Ehrlish's reagent and a reddish brown color spot when dipped in freshly prepared ferric chloride solution.

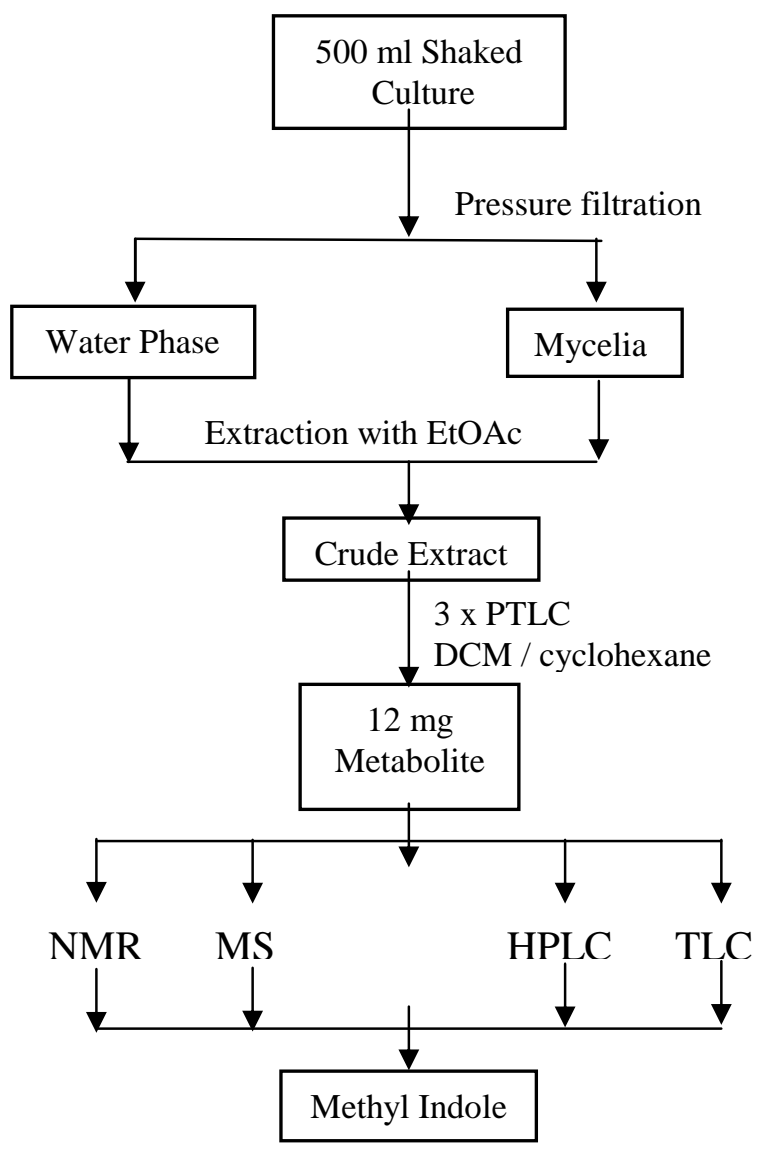

Fig. 1: Work-up of the strain GW 14/587

\section{Antimicrobial activity}

Antibacterial, antifungal and antimicroalgal (phycotoxic) activities were estimated by the agar diffusion method using paper discs of $8 \mathrm{~mm}$ diameter. Each paper disc impregnated with $50 \mu \mathrm{g}$ of tested culture extract was placed on agar media suspended with test microorganisms. Inhibition zones were observed after incubation at $27^{\circ}$ for 24 hours for yeast and 48 hours for fungi, and microalgae and at $37^{\circ}$ for 24 hours for bacteria. $^{18}$

\section{RESULTS AND DISCUSSION}

The structure of the metabolite obtained from four, five and six day-old culture concentrates was established as methyl indole $\left(\mathrm{C}_{9} \mathrm{H}_{9} \mathrm{~N}\right)$ using different spectroscopic analyses. EI-MS showed a base peak at $\mathrm{m} / \mathrm{z} 130.1$ and a parent peak at 131.1 for $\mathrm{M}^{+}$(Figure 2), while HPLC-MS (+ve) ESI showed a base peak at 132.2 for $\mathrm{M}^{+1}$ which appeared at $\mathrm{R}_{\mathrm{t}} 14.45 \mathrm{~min}$ (Figure 3). ${ }^{1} \mathrm{H}-\mathrm{NMR}$ showed peaks at $\delta=8.05$ $\operatorname{ppm}(s, \mathrm{br}, 1 \mathrm{H}, \mathrm{H}-\mathrm{N}), \delta=7.65(d, \mathrm{~J}=7.5 \mathrm{~Hz}, 1 \mathrm{H}$, $\mathrm{H}-4), \delta=7.39(d, \mathrm{~J}=7.5 \mathrm{~Hz}, 1 \mathrm{H}, \mathrm{H}-7), \delta=7.24$ $7.06(m, 2 \mathrm{H}, \mathrm{H}-5$ and $\mathrm{H}-6), \delta=6.95(s, 1 \mathrm{H}, \mathrm{H}-2)$ and at $\delta=2.30\left(s, 3 \mathrm{H}, \mathrm{CH}_{3}\right)$ (Figure 4$) .{ }^{13} \mathrm{C}$ NMR showed nine peaks at $\delta \mathrm{ppm} 136.22 \mathrm{C}$ 7a, $\delta 128.22 \mathrm{C}-4 \mathrm{a}, \delta 121.81 \mathrm{C}-2$, $\delta 121.51 \mathrm{C}-4$,

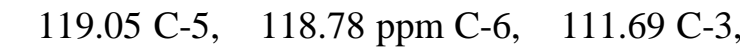
$\delta 110.89 \mathrm{C}-7$ and at $\delta 9.66 \mathrm{CH}_{3}$ (Figure 5). APT $-{ }^{13} \mathrm{C}-\mathrm{NMR}$ shows the quaternary carbons C-2, C-4a and C-7a appear down the spectrum base line (Figure 6).<smiles>Cc1c[nH]c2ccccc12</smiles>

Methyl Indole $\mathrm{C}_{9} \mathrm{H}_{9} \mathrm{~N}$

This data was confirmed by comparison with data from AntiBase $^{19}$ using molecular weight and the substructures determined from the ${ }^{1} \mathrm{H}-\mathrm{NMR}$ data. ${ }^{20}$ Although methyl indole has been previously synthesized as the known compound Skatole, ${ }^{21}$ this is the first report of its isolation from the Streptomycete strain GW $14 / 587$ as a result of biotransformation of the indole base fed into the growth media.

It was reported that ${ }^{22}$ acriflavine treatment of Streptomyces generated a bald mutant that produced two carbazole derivatives, where DNA intercalated the acriflavine dye by mutagenisis. The mechanism of Streptomycete strain GW $14 / 587$ to synthesize methyl indole from the indole fed in the media is still under investigation; however mutagenisis could be a possible mechanism. 


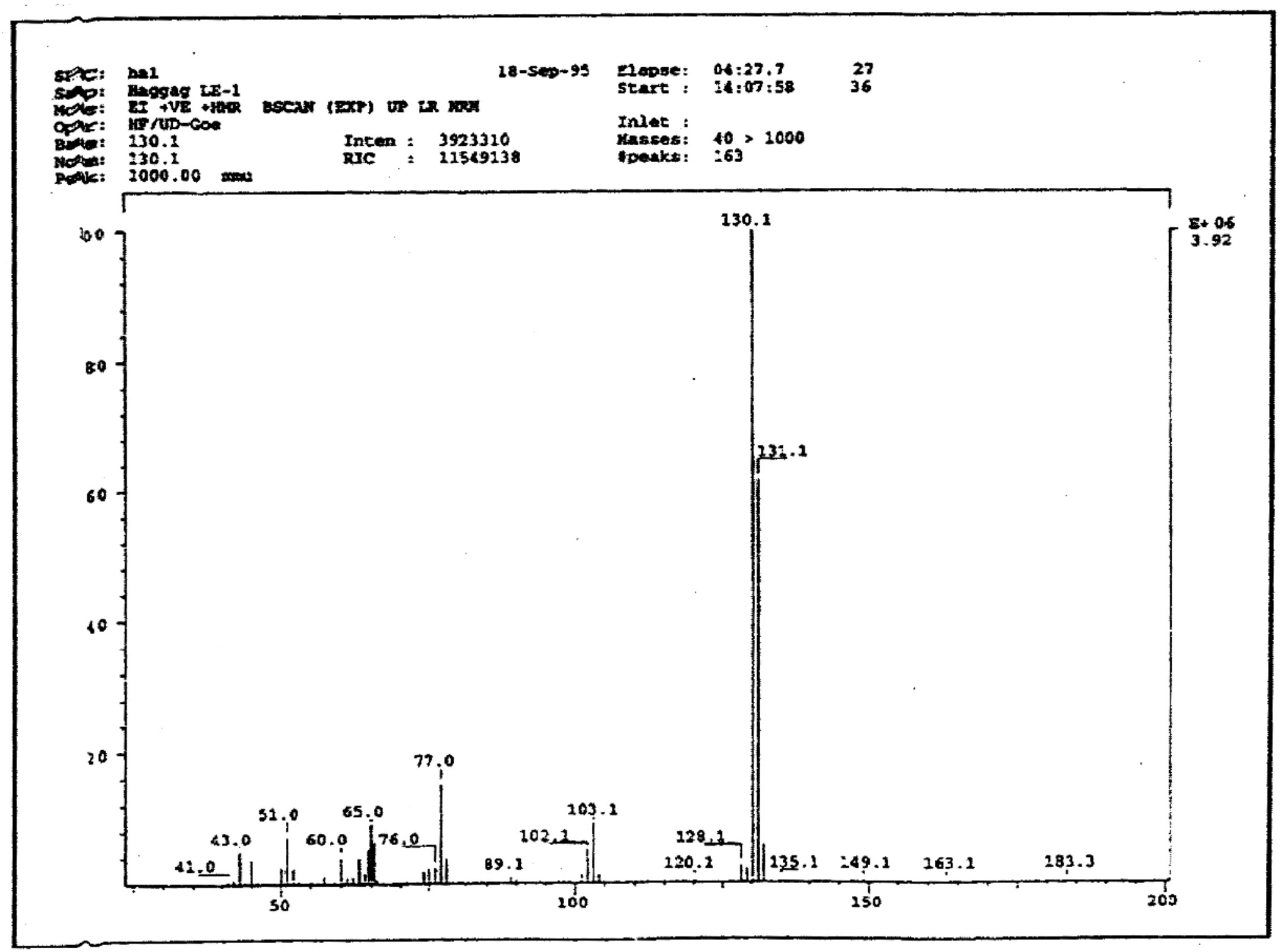

Fig. 2:EI-MS spectrum of methyl indole. 


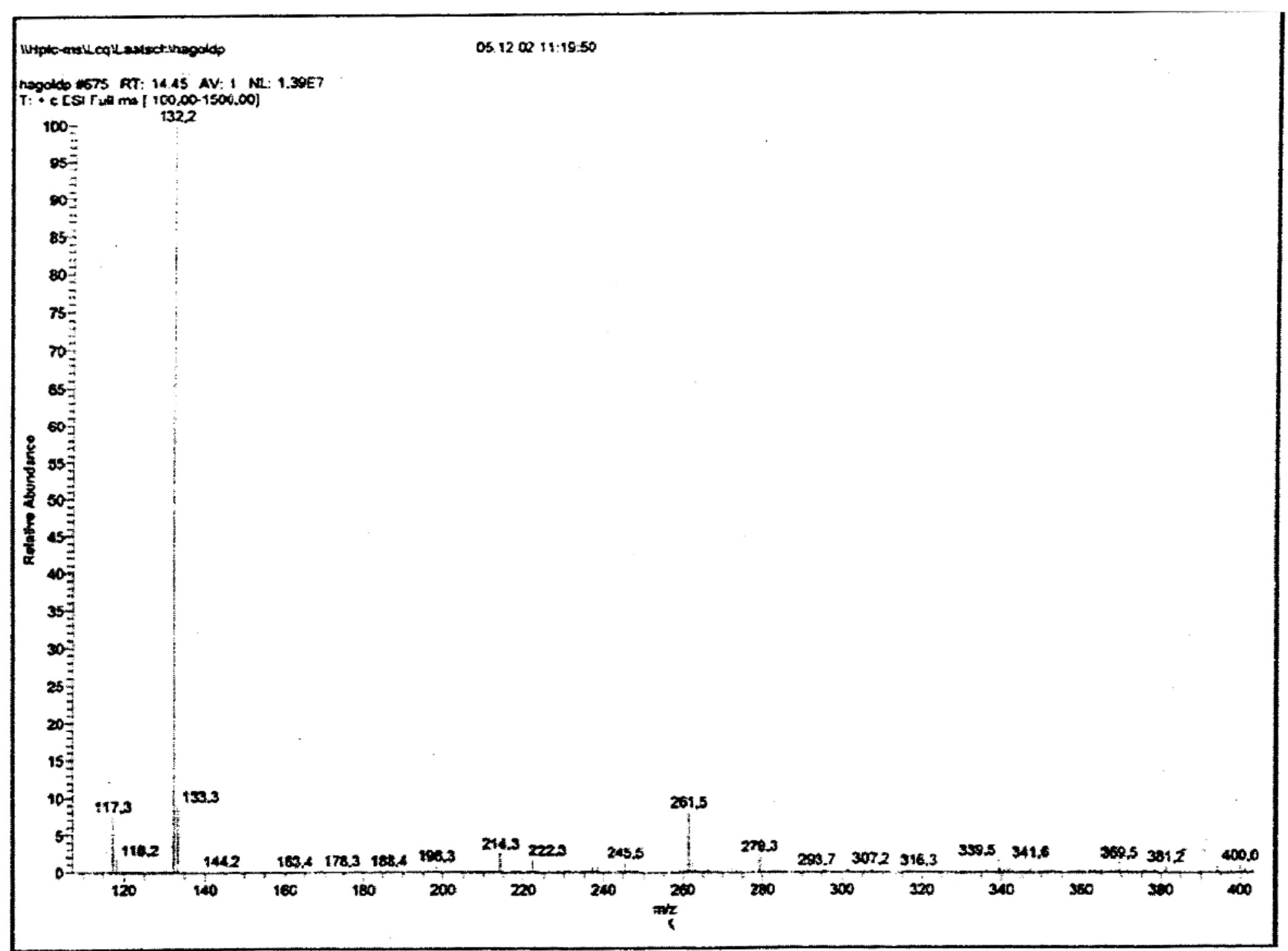

Fig. 3: HPLC-MS (+ve) ESI spectrum of methyl indole. 


$$
6-1
$$




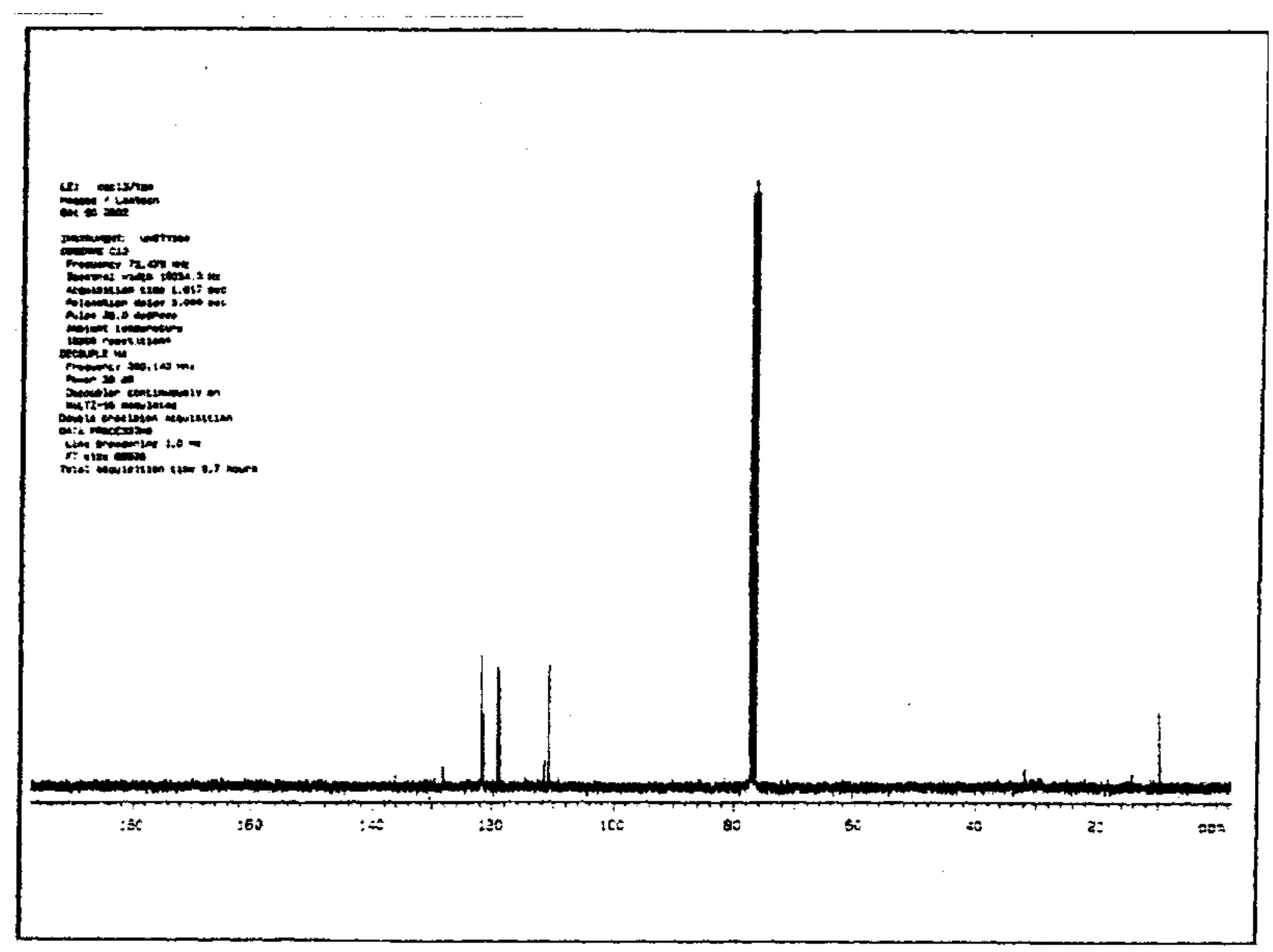

Fig. 5: ${ }^{13} \mathrm{C}-\mathrm{NMR}$ spectrum of methyl indole. 


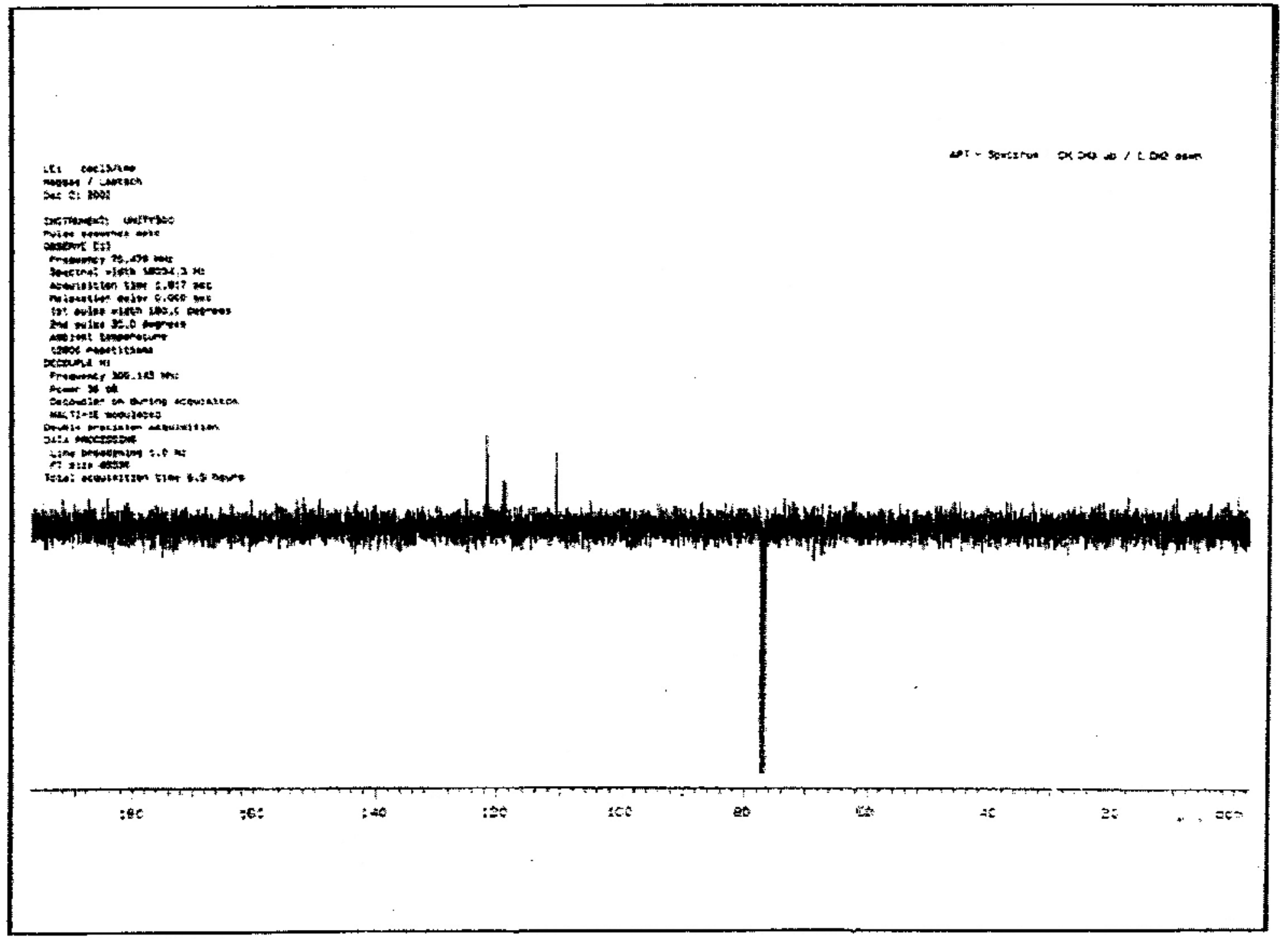

Fig. 6: $\mathrm{APT}{ }^{13} \mathrm{C}-\mathrm{NMR}$ spectrum of methyl indole. 
Table 1: Antimicrobial activities of Streptomycete strain GW 14/587 (Parental and indole-fed) culture extracts compared to germanomycine.

\begin{tabular}{|c|c|c|c|c|c|c|c|c|c|}
\hline & EC & BS & SV & SA & MM & CA & CV & CS & SS \\
\hline $\begin{array}{c}\text { Crude extract of } \\
\text { parental culture }\end{array}$ & 0 & 11 & 18 & 0 & 0 & 12 & 15 & 15 & 17 \\
\hline $\begin{array}{c}\text { Crude extract of } \\
\text { indole-fed culture }\end{array}$ & 10.5 & 11 & 11 & 11 & 0 & 0 & 12 & 12 & 50 \\
\hline $\begin{array}{c}\text { Germanomycine } \\
\text { (+ve control) }\end{array}$ & 25 & 28 & 22 & 19 & 0 & 0 & 7 & 6.5 & 0 \\
\hline
\end{tabular}

Diameters of inhibition zones in $\mathrm{mm}$.

$(\mathrm{EC}=$ Escherichia coli $; \mathrm{BS}=$ Bacillus subtilis; $\mathrm{SV}=$ Streptomyces viridochromogenes; $\mathrm{SA}=$ Staphylococcus aurens; $\mathrm{MM}=$ Mucor miehei; $\mathrm{CA}=$ Candida albicans; $\mathrm{CV}=$ Chlorella vulgaris; $\mathrm{CS}=$ Chlorella sorokiniana; $\mathrm{SS}=$ Scenedesmus subspicatus)

The high yield of methyl indole produced by the four-days old culture crude extract $(12 \%)$ was encouraging to test it for antimicrobial activity (Table 1). Feeding Streptomycete strain GW 14/587 with indole has changed the antibiotic pattern of the parent strain. As shown in Table 1 the crude extract of the culture fed with indole in its malt media showed in addition to the antibacterial activity of the parent strain against Bacillus subtilis and Streptomyces viridochromogenes, a moderate activity against Escherichia coli and Staphylococcus aurens. The parent culture showed moderate activity against the yeast Candida albicans, while the fed indole culture extract showed no activity. It was also found that the indole fed culture extract has a remarkably stronger selective antimicroalgal activity against Scenedesmus subspicatus than the parent crude extract which showed the same moderate phycotoxic activity against the three tested microalgae Chlorella vulgaris, Chlorella sorokiniana and Scenedesmus subspicatus. Both cultures showed no activity against the fungus Mucor miehei.

\section{Conclusion}

Terrestrial Streptomycete strain GW $14 / 587$ showed the ability to synthesize methyl indole from indole fed into its growth media. The biotransoformation of indole resulted in a strong active antimicroalgal agent against Scenedesmus subspicatus.

\section{Acknowledgement}

The authors would like to thank Mrs. Fredricke Lissy, Dept. of Organic Chemistry, George-August University, Gottingen, Germany, for her technical assistance.

\section{REFERENCES}

1- J. d. Faulkner, Nat. Prod. Rep., 18, 1-49 (2001).

2- B. S. Davidson, Curr. Opin. Biotec., 6, 284-91 (1995).

3- W. Fenical, and P. R. Jensen, Annu. Rev. Microbiol., 48, 559-84 (1994).

4- M. Shaaban, R. P. Maskey, I. WagnerDobler and H. Laatsch, J. Nat. Prod., 65, 1660-3 (2002).

5- J. Kobayashi and M. Ishibashi, In: The Alkaloids, A. Brossi and G.A. Cordell, eds., Academic Press, N.Y., Vol. 41, Chapter 2, 1992, pp. 41-124.

6- C. Christophersen, In: The Alkaloids, A. Brossi ed., Academic Press, N.Y., Vol. 24, Chapter 2, 1985, pp. 25-111.

7- C. Christophersen, In: Marine Natural Products: Chemical and biological perspective, P. J. Scheuer Ed.; Academic Press, N.Y., Vol. 5, Chapter 5, 1983, pp. 259-85.

8- M. Alvarez and M. Salas, Heterocycles, 32, 1391-429 (1991).

9- J. Sapi and G. Massiot, In: The Alkaloids, G.A. Cordell, ed., Academic Press, N.Y., Vol. 47, Chapter 3, 1995, pp. 173-226. 
10- G. W. Gribble, In: Progress in the Chemistry of Organic Natural Products, W. Herz, R.E. Moore, W. Steglich and C. Tamm eds., Springer Wein, N.Y., Vol. 68, Chapter 3, 1996, pp. 141-60.

11- M. A. F. Biabani, M. Baake, B. Lovisetto, H. Laatsch, E. Helmke and H. Weyland, J. Antibiot., 51, 333-40 (1998).

12- V. J. Mukku, M. Speitling, H. Laatsch and E. Helmke, J. Nat. Prod., 63, 1570-2 (2000).

13- R. N. Asolkar, R. P. Maskey, E. Helmke and H. Laatsch, J. Antibiot., 55, 893-8 (2002).

14- R. P. Maskey, E. Helmke and H. Laatsch, J. Antibiot., 56, 942-9 (2003).

15- M. Abdelfattah, R. P. Maskey, R. N. Asolkar, I. Grun-Wollny and H. Laatsch, J. Antibiot., 56, 539-42 (2003).
16- S. Fotso, R. P. Maskey, I. Grun-Wollny, K. P. Schulz, M. Munk and H. Laatsch, J. Antibiot., 56, 931-41 (2003).

17- H. Weyland, Zbl. Bakt. Supp., 11, 185-93 (1981).

18- B. S. Yun, I.K. Lee, Y. Cho, S. M. Cho I. D. Yoo, J. Nat. Prod., 65, 786-8 (2002).

19- H. Laatsch, AntiBase 2000, A natural product Database for rapid structure determination, Chemical Concepts, Weinheim 2000, see Internet, http//www.gwdg.de/ ucoc/laatsch/.

20- C. J. Pouchert and J. Behnke, The Aldrich library of ${ }^{13} \mathrm{C}$ and ${ }^{1} \mathrm{HT}$ NMR spectra, 1993, pp. 121-2.

21- Sigma-Aldrich, Biochemicals and Reagents: for life science research, 2003, p. 1337.

22- H. Grammel, H. Wolf, E. D. Gilles, F. Huth and H. Laatsch, Z. Naturforsch, 53, 325-30 (1998). 